\title{
IoT Teknolojisi Kullanan Pratik ve Güvenilir Akıllı Kapı Kilidi Tasarımı
}

\author{
Ayşegül Kalyoncu ${ }^{1 *}$, Metin Turan ${ }^{2}$ \\ 1 İstanbul Ticaret Üniversitesi, Mühendislik Fakültesi, Bilgisayar Mühendisliği Bölümü, İstanbul, Türkiye (ORCID: 0000-0002-6205-6849) \\ 2 İstanbul Ticaret Üniversitesi, Mühendislik Fakültesi, Bilgisayar Mühendisliği Bölümü, İstanbul, Türkiye (ORCID: 0000-0002-1941-6693)
}

(Bu yayın 26-27 Haziran 2020 tarihinde HORA-2020 kongresinde sözlü olarak sunulmuştur.)

(DOI: 10.31590/ejosat.779045)

ATIF/REFERENCE: Kalyoncu, A. \& Turan M. (2020). IoT Teknolojisi Kullanan Pratik ve Güvenilir Akı1ll Kap1 Kilidi Tasarımı. Avrupa Bilim ve Teknoloji Dergisi, (Special Issue), 43-49.

$\ddot{O} z$

Teknolojinin hızla gelişmesi ve internetin yaygınlaşması, ayrıca modern yaşamın ortaya çıkardığı ihtiyaçlar dolayısıyla Nesnelerin İnterneti (IoT)'ne olan ilgi gün geçtikçe artmaktadır. IoT artık yaygın olarak kullandığımız, sürekli duyduğımuz bir kavram olmuştur. "Akıllı sistemler" olarak adlandırdığımız IoT uygulamaları, ev, tarım ve sağlık alanları başta olmak üzere neredeyse birçok alanda karşımıza çıkmaktadır. Bu çalışmada "Akıllı Ev" sisteminin bir parçası olarak algılanabilecek, kapı kontrol IoT uygulaması geliştirilmiştir. Projenin motivasyonunu, sık sık karşılaşılan bir durum olan evin dış kapısında kalan birisinin (çocuk, bakıc1), uzak konumdaki ev sahibine durumunu haberdar ederek, güvenli bir biçimde IoT teknolojisi ile kapınm açılabilmesi oluşturmaktadır. Süreç, kapıdaki kişinin telefonunda bulunan Android uygulama ile ev sahibine (genellikle ebeveyn) kapının açılması için istekte bulunması ile başlar. Bu istek, Raspberry Pi üzerindeki PHP Web servisinin uyarılması ve Python ile kodlanmış yazılım kullanılarak kamera görüntüsünün ev sahibine mail olarak gönderilmesi ile devam eder. Nihai olarak, ev sahibinin telefonunda olan diğer Android uygulama ile onay verilirse Raspberry Pi üzerindeki diğer PHP Web servisinin uyarılması sonucu elektrikli kapı kilidine yeterli gerilim verilerek kapının açılması ile sonlanır. Özellikle, düşük maliyetli ve güvenlik ihtiyaçları gözetilerek geliştirilmiş, pratik olarak uygulanabilir bir çalışmadır.

Anahtar Kelimeler: Akıllı Ev Uygulamaları, Nesnelerin Interneti, Raspberry Pi

\section{Practical and Reliable Smart Door Lock Design Using IoT Technology}

\begin{abstract}
Due to the rapid development of technology and the widespread of the internet, and the needs of modern life, the interest in the Internet of Things (IoT) is increasing day by day. IoT is now a concept that we use extensively and that we constantly hear. IoT applications, which we call "smart systems", appear in many areas, especially in the fields of home, agriculture and health. In this study, door control IoT application, which can be perceived as a part of "Smart Home" system, has been developed. The motivation of the project is the fact that someone (child, childminer) who is at the outer door of the house, which is a frequent situation, can be opened safely with IoT technology by informing the home owner in the remote location. The process starts with the request by the cell phone of the person on the door using installed Android application to the homeowner (generally parent) to open the door. This request continues by activating the PHP Web service on Raspberry Pi and sending the camera image to the homeowner via an e-mail, using Python-encoded software. Ultimately, if it is approved by the other Android application on the homeowner's phone, it will end with the opening of the door by giving sufficient voltage to the electric door lock as a result of the activation of the other PHP Web service on the Raspberry Pi. In particular, it is a practically feasible study, developed with low cost and security needs in mind.
\end{abstract}

Keywords: Smart Home Applications, IoT, Raspberry Pi

\section{Giriş}

Son zamanlarda bilgisayarların, akıllı telefonların ve internetin kullanımı önemli ölçüde artmıştır. Bu artış insanların yaşamına kolaylıklar sağlamasına rağmen birçok olumsuz yanı da hayatımıza girmiştir. Bu sorunlardan en önemlisini "güvenlik" oluşturmaktadır. Geliştirilen tüm akıllı sistemlerde bulunması zaruri gözüken temel özellik, güvenliğin en üst düzeyde sağlanmasıdır. 
Makaleye konu olan çalışmada, bir "akıllı kapı kilidi” modeli önerilmiştir. Bu problem, diğer birçok uygulama gibi hem veri, hem de uygulama güvenliği ile yakından ilişkilidir. Veriler internet ortamında iletildiğinden ve karmaşı uygulama platformundan dolayı iki güvenlik ayağı da dikkatlice ele alınmalıdır. Motivasyon sağlayan problem, ev sahiplerinin, çocukların, yaşlıların anahtarlarını unutması durumuyla ilişkilidir. Ebeveynler uzak bir yerde, hatta şehir dışında bulunuyorsa problem daha da kronikleşmektedir. Gerçek hayat problemi olan bu duruma çözüm üretmek ihtiyacı, akıllı kapı sistemlerine olan ilgiyi daha da artırmıştır.

Akıllı kapı sistemleri hakkında çok çeşitli araştırmalar yapılmışır. Bunlardan Bluetooth teknolojisini kullanarak yapılan çalışmalara ilk örnek Nehru ve arkadaşları (2015) tarafından yapılan çalışma verilebilir. Bu çalışmada, ARM denetleyicisine dayalı bir ev otomasyon tekniği geliştirmişlerdir. Bu teknik kişiyi tespit etmek için bir IR algılayıcısı kullanmaktadır. IR algılayıcısı bir kişi algılarsa, geçiş kodunu girebilmek üzere tuş takımı etkinleştirir. Ayrıca kimlik doğrulaması için yetkili kişiye bir SMS gönderilir. Yetkili kişi onayı ile kapı açılır. Kapıda bekleyen kişi yanlış bir şifre girerse, sahibine bir bildirim mesajı gönderilir ve ayrıca sesli uyarı etkinleştirilir [1]. Han ve arkadaşları (2017) ise yaptıkları çalışmada, akıllı kapı kilidi sistemine gönderilen ve alınan verilerin sahteciliğe ve çökertilmeye karşı savunmasız olmasını ele almışlardır. Bu güvenlik sorunlarını iyileştirmek üzere, blok zinciri (block-chain) tabanılı bir akıllı kapı kilidi sistemi önermişlerdir [2]. Diğer bir önemli çalışmada, Hadis ve arkadaşları (2018) bir kapı açmak veya kilitlemek için doğrudan temas gerektirmeyen kilit sistemini geliştirmiş̧lerdir. Ayrıca, kilit sistemi farklı fiziksel özelliklere sahip insanlar tarafından da kullanılabilir niteliktedir. Sistem düşük güçle Bluetooth teknolojisini kullanmaktadır ve neredeyse tüm cihazlarda kullanılabilmesi amaçlanmıştır [3]. Arifin ve arkadaşları (2018) tarafindan önerilen modern sistemde, akıllı telefon uygulamasına konuşma komutu veya şifre girilerek kimlik doğrulaması ile kapı kilidinin açılması üzerine bir çalışma örneklenmiştir. Önerilen yöntemde, Android akıllı telefon uygulaması seri iletişim için Bluetooth kullanmaktadır. Düşük maliyetinin yanı sıra, kablosuz ev otomasyon sistemi olarak kolayca uygulanabilirdir [4].

Bluetooth teknolojisine ek olarak görüntü işleme teknolojisi de kullanan çalışmalar bulunmaktadır. Örneğin, Adalan ve Erkmen (2016) Android işletim sistemine sahip bir akıllı telefon üzerinde geliştirilen mobil uygulamayı kûllanılarák, yüz tanıma, NFC (Near Field Communication) ve ses komutu ile kapı kilidi sistemine erişimi kablosuz haberleşme kullanarak gerçeklemişlerdir. Akıllı telefona ses komutu iletilerek ve telefonun NFC etiketine yaklaştırılmasıyla kapı kilidi sistemi kontrol edilmiş̧tir. Ayrıca kapı kilidi sisteminin kontrolünde yüz tanıma işleminden de yararlanılmıştır [5]. Kavde ve arkadaşłarı (2017) "akıllı dijital kilit" sistemini kullanarak, kullanıcının canlı yayın yoluyla kimlik doğrulaması yapabilmekte, Bluetooth aracılığı ile kapłıı açabilmekte ve bekleyen kişinin eve girmesine izin verebilmektedir. Bu çözüm, çalışan anne ve meşgul aileler için, çocukları veya beklenen kişiler için bir kişinin evde bulunması gerekliliğini ortadan kaldırmış olmaktadır [6].

Daha gelişmiş Wi-fi teknolojisini kullanan araştırmalara da rastlanmaktadır. Bunlardan Mrinal ve arkadaşları (2017) önerdiği sistemde, bazı işlevlere sahip ev otomasyonunun, Wi-Fi internet bağlantı protokolü ile kontrol edilmesi üzerinde çalışmışlardır. İşlevler arasında alarm tabanlı akıllı kilit, ev aletlerini uzaktan kumanda etmek, sivrisinek algılama ve akıllı su deposu bulunmaktadır [7]. Rajadurai ve arkadaşalrı (2017) tarafindan önerilen diğer bî sistemde, kapı kilidine gömülü WeMos D1 Wi-Fi birimi ve Firebase bulut mesajlaşma servisiyle iletişim kuran bir Android uygulaması kullanılarak, Wi-Fi protokolü ile kapı kilidi kontrol edilmektedir. Cep telefonu uygulaması, kapı kilit sistemine güvenli erışim için güvenli bir kullanıcı şifresi ile kişiselleştirilmiştir. Sistem kullanıcının kimlik bilgilerini doğrular ve ardından bulut tabanlı güvenli mesajlaşma servisini kullanarak mobil uygulama ara yüzüne bir OTP gönderir ve kapının açılıp açılmadığını kontrol eder [8]. Wi-fi teknolojisi ile birlikte görüntü işleme teknolojisi de kullanan diğer bir çalışmada Vaidya ve arkadaşları (2017) Python, OpenCV ve Android uygulamaları ve Raspberry Pi kartını kullanarak, bir akıllı ev otomasyon sistemi önermişlerdir. Sistem, Android uygulama aracıllğı ile telefondan erişilebilen, ana kapının dışına monte edilmiş bir kameradan yüz tanımaya dayalı olarak tasarlanmıştır. Bu çalışmanın en yenilikçi özelliğini, tüm cihazların kullanıcı sesiyle kontrol edilebilmesi oluşturmaktadır [9].

Sadece görüntü işleme kullanan, Kìn ve arkadaşalrı (2013) tarafından yapılan çalışma, bir kapı telefonu aracılı̆̆ıyla yabancı yüzleri daha verimli ve doğı bir şekilde tanımlamak üzere, hem yüz tanıma hem de ses yerelleştirme tekniklerini içermektedir. Özellikle, bir ziyaretçinin sesi konuşmacının doğru konumunu belirlemek için kullanılmaktadır. Daha sonra bu konum bilgisi kullanılarak, kapı telefonu kamerasının kanumu güncellenmekte, görüş alanındaki yüz çerçevelenerek görüntü alınmaktadır. Ziyaretçinin yüz konumunu doğru bir şekilde bulmak iç̣̂n 4 ayrı mikrofon çapraz yapılandırmaya yerleştirilmiștir. Ayrıca, ziyaretçiyi tanımak ve bilgileri ev sahibinin telefonuna göndermek için yüz algılama ve yüz tanıma algoritmaları ile kablosuz bir arabirim de kullanılmaktadır. Tüm kontrol sistemi birFPGA yongası kullanılarak üretilmiştir ve kapı telefonu ortamlarında gerçek kullanım için test edilmiştir [10].

Bulut bilişim teknolojisi kullanan Faiz ve arkadaşarı (2017) tarafından geliştirilen modelde, akıllı telefona kurulan bir Android uygulaması tarafundan kontrol edilebilen bir akıllı kapı sistemi önerilmiştir. Kapının hareketini kontrol etmek üzere Raspberry Pi ve ilgili gömülü yazılım kullanılmaktadır. Hareket duyargaları, kapının önündeki herhangi bir hareketi tespit etmek için kullanmaktadır. Herhangi bir kişi kapının önüne gelirse, algılayan duyarga tetiklenmekte, resim çekilerek ilgili kişilere bildirilmektedir [11]. Muthumari ve arkadaşları (2018) kamera özelliğine sahip akıllı telefonla kapıda bulunan kişi / kişilerin fotoğrafını çekerek, Wi-Fi yardımıyla kapının açılabilmesini sağlayacak bir sistem önermişlerdir. Yetkili kişi kapı önünün görüntüsünü görebilir, akıllı kapı kilidini açabilir veya bir cihazla da kilitleyebilir. Evin içinden Bluetooth ile kapının kilidini açmak mümkündür ve hatta çocuk veya yaşlı insanların WiFi menzilinde oldukları durumda telefonla kapı kilidini açabilmeleri bazı özel durumlarda (felçli, engelli hastalar) oldukça faydalıdır. Bunun için ev üyelerinin uygulamayı kendi akıllı telefonlarına yüklemeleri yeterli olacaktır. Böylece, engellilerin kimseden yardım almadan kapıyı açabilmesine ve normal bir yaşam sürebilmesine yardımcı olunacaktır [12].

Diğer teknolojileri kullanan Park ve arkadaşları (2009) tarafından yapılan çalışmada, ev otomasyonu için akıllı bir dijital kapı kilit sistemi önerilmiştir. Burada önerilen kapı kilit sistemi, kullanıcı kimlik doğrulaması için RFID okuyucu, dokunmatik LCD, kapının açılması ve kapatılması için motor birimi, evin içindeki durumu tespit etmek için algılayıcı birim, iletişim birimi ve diğer birimleri kontrol etmek üzere kontrol birimlerinden oluşmaktadır [13]. Bir diğer uygulama ise, Lita ve arkadaşarı (2017) tarafindan yapılmış, 
burada akıllı evlerde erişim kontrolü amacı ile kullanılabilecek bir pnömatik (gaz basıncını mekanik harekete dönüştüren) kapı otomasyon sisteminin tasarımı ve örnek uygulaması sunulmuştur. Geliştirilen uygulamanın yapısı, selenoid valfli bir hava dağıtıcısı aracılığıyla kontrol edilebilen çift etkili bir silindiri süren bir pnömatik motor ve onu kontrol eden PIC 16F877A mikro-denetleyicisinden oluşmaktadır [14].

Bu araştırma kapsamında, açıklanan mevcut problem (kapıda anahtarsız kalma durumu) göz önüne alınarak güvenli bir akıllı kapı sistemi modeli önerilmiş ve uygulanmıştır. Geliştirilen Android "Kapıda Kaldım" sayesinde, kapının açılmasını isteyen kişi, Raspberry Pi üzerinde konumlanmış basit web servisi aracılığ 1 ile kapı açma yetkisi olan kişi veya kişilere (sistemde tanımlanmış e-posta adresleri kullanılarak) kamera ile alınmış kapı resmini içeren bir e-posta gönderebilmektedir. Eğer kapı açmaya yetkili kişi gönderilen e-postadaki kişiyi doğrularsa, kapı Raspberry Pi üzerinde konumlanmış basit web servisinin, yetkili kişinin telefonunda bulunan "Kapıyı Aç" Android uygulaması ile çağrılması sonucu açılabilmektedir. Web servisleri Raspery Pi ile bağlantılı donanım cihazlarını (kamera, manyetik kilit) kontrol eden Python kodlarını çağırırlar. Önerilen model, çok katmanlı ve tamamen güvenilir bir sistem olarak tasarlanmış, ayrıca pratik olarak uygulanabilmesi için maliyeti minimum tutulmuştur.

Bu makalenin geri kalan kısmı, 2. bölümün de ilgili kavramlar, 3. bölümünde sistem tasarım modeli ye 4. bölümde sonuç ve gelecekteki çalışmalardan olacak şekilde düzenlenmiştir.

\section{2. İlgili Kavramlar}

\subsection{Nesnelerin İnterneti (İnternet of Things-Iot)}

Nesnelerin İnterneti, kablosuz telekomünikasyon cihazlarının yeni bir bağlantı şeklidir. Akıllı telefonlar, Akıllı şehirler, Akı1lı cihazlar ve akı1lı bir dünya IOT'nin akıllı vizyonudur. IOT'nin temel amacı günlük yaşamımızda ortak bir husustur ve kullanıcıların davranışlarına bağlı olarak gelişmektedir. [15].

Çalışmada IoT ağı kapıda kalan kişinin cep telefonu, kapı açma yetkisi olan kişinin cep telefonu ve mini bilgisayardan (Rapberry Pi) oluşmaktadır. Cep telefonları IoT cihazı olabilmek için özel bir ağa-VPN), gelisstirilmiş bir Android uygulaması ile bağlanabilmektedirler. Bu uygulama ayrıca kullanıcıdan yetki bilgilerinin (kullanıcı adı ve șifré) alınmasını zorunlu kılarak güvenliği üst düzeye çıkarmaktadır.

\subsection{Akıllı Ev (Smart Home)}

Akıllı ev, otomatik işlevleri olan ve kullanıcı tarafindan uzaktan kontrol edilebilen sistemlere sahip cihazları içerir. Akıllı bir evin temel amacı, ev sakinleri için konfor, enerji tasarrufu ve güvenliği arttırmaktır. [16]. Çalışmada, ev kapısının uzaktan kontrol ile açılması üzerine "akıllı ev" uygulaması örneklenmiştir. Uzaktan kontrol için internet alt yapısı kullanılmaktadır. İnternete bağlı olan bir cep telefonu ve kapıyı kontrol eden bir elektronik kart (Rapberry Pi) ile çözüm sunulmaktadır.

\subsection{Akıllı Kapı (Smart Door)}

Akıllı kapı, dijital kod, şifreler, tarama ve parmak izi taraması, göz taraması veya retina taraması gibi tanıma faktörleri temelinde çalışan bir yapıdır [17]. Çalışmada ele alınan akılı kapı modelinde fiziksel temas söz konusu değildir. Bunun yerine akıllı kapı uzaktan yetki kullanarak kumanda edilebilen (açılıp/kapatılabilen) bir sistemdir. Çalışmanın sınırları ise sadece kapının açılma özelliğini kullanmaya yönelik olarak belirlenmiştir

\subsection{Raspberry Pi}

Raspberry Pi, düsük maliyetli, mini birr bilgisayardır [18]. Çalışmada, bu bilgisayar üzerine Raspbian işletim sistemi ve Apache sunucu yüklenmiştir. Bu sayede internet istemleri web sunucu üzerinde bulunan web servisleri kullanılarak ve kapı kontrolü ise Python dilinde kodlanmış uygulamalar aracıllı̆̆ ile yürütülmektedir.

\section{Materyal ve Yöntem}

Bu çalışmada önerilen sistem, kapıda kalan bireyin (çocuk, yaşlı, bakıc1) akıllı cep telefonunda bulunan Android uygulama sayesinde kapı açılma isteğinde bulunabilmesi, ev sahibi konumunda bulunan yetişkin bireyin (anne, baba) akıllı cep telefonunda bulunan diğer bir Android uygulama sayesinde kapıyı açabilmesi üzerinedir. Çok katmanlı yapı ile kapı gibi önemli bir donanım üzerinde maksimum güvenlik sağlanmaya çalışılmıştır.

Sistemin detaylı uygulama süreci, kapıdaki kişinin telefonunda bulunan Android uygulama ile ev sahibine (genellikle ebeveyn) kapının açılması için istekte bulunması ile başlar. Bu istek, Raspberry Pi üzerindeki PHP Web servisinin uyarılması ve Python ile kodlanmış yazılım kullanılarak kamera görüntüsünün ev sahibine mail olarak gönderilmesi ile devam eder. Nihai olarak, ev sahibinin telefonunda olan diğer Android uygulama ile onay verilirse Raspberry Pi üzerindeki diğer PHP Web servisinin uyarılması sonucu elektrikli kapı kilidine yeterli gerilim verilerek kapının açılması ile sonlanır. Akıllı cep telefonları ve Raspberry Pi güvenli bir şekilde veri alışverişi yapabilmesi için OpenVPN kullanılmıştır. Genel sistem şeması Şekil 1'de gösterildiği gibidir. 


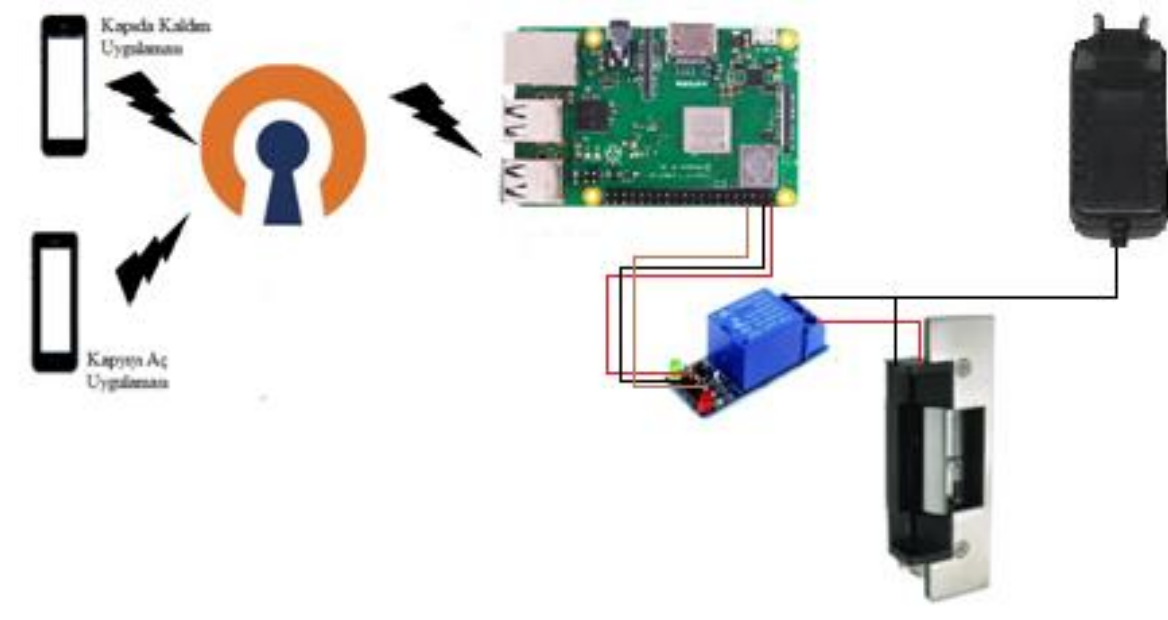

Şekil 1. Sistemin genel yapist.

Sistem üzerinde çok farklı donanım ve yazılım ürünleri kullanılmıştır. Akıllı kart olarak Raspberry Pi B+ modeli belirlenmiştir. Bu mini bilgisayarı projede kullanabilmek için, sırasıyla aşağıdaki adımlar uygulanmıştır:

1. Raspbian işletim sistemi kurulmuştur.

2. Web kameradan fotoğraf almak için OpenCV kurulumu yapılmıştır.

3. Çekilen fotoğrafi Raspberry Pi'den göndermek için projeraspberry@ @mail.com isimli e-posta adresi tanımlanmıştır.

4. Gönderilen e-postayı ev sahibinin alması için proje.human@ gmail.com isimli e-posta adresi alınmıştır.

5. Raspberry Pi ile, akıllı cep telefonunda bulunan Andorid Studio üzerinde geliştirilen uygulama yazılımının birbirleriyle iletişim kurabilmesi için Apache (web sunucu), Myadmin ve Flașk kurulmuştur.

6. IoT ağındaki cihazların güvenilir bir şekilde iletişim sağlamaları için OpenVpn kurulmuştur. OpenVpn hem akıllı cep telefonlarına hem de Raspberry Pi' ye kurulmuştur.

Ayrıca Android uygulamalarında yer alan kullanıcı ve şifre girişlerine ait panel bilgilerinin kontrolü için FireBase veri tabanı kurulmuştur. Kapının açılması esnasında Raspberry Pi'yi yüksek akımlara karşı korumak için bir röle kullanılmıştır.

Android uygulamalarında güvenliği artırmak üzere e-posta ve şifre giriş paneli tasarlanmıştır. Bu basit ekranın görüntüsü Şekil 2' de gösterildiği gibidir. Benzer yetkili giriş ekranı "Kapıda Kaldım” Android uygulaması içinde kullanılmaktadır.

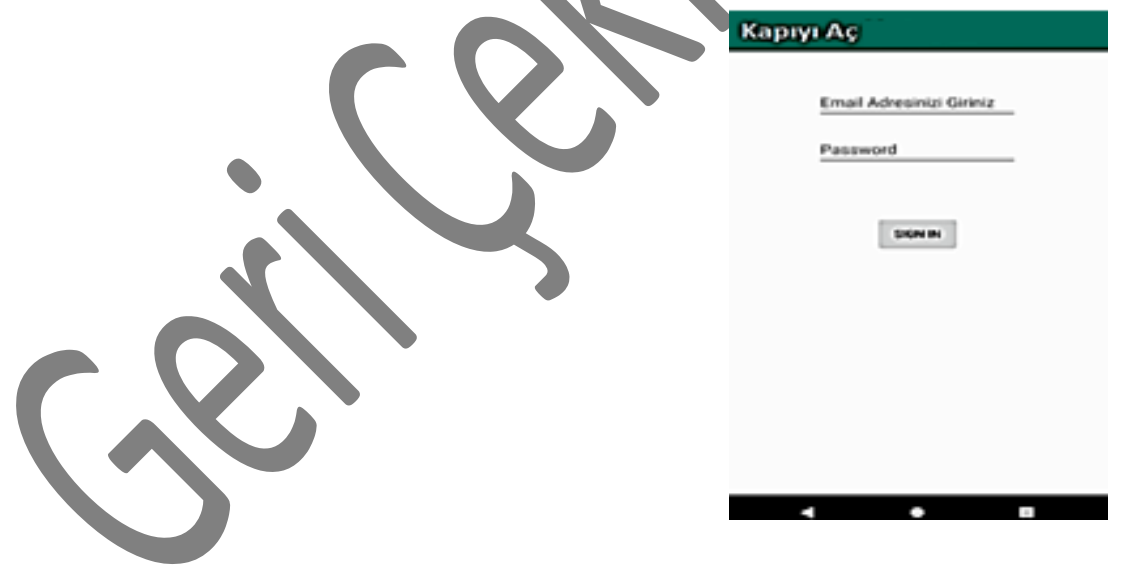

Şekil 2. "Kapıyı Aç” android uygulaması giriş paneli.

"Kapıda Kaldım" Android uygulamasında e-posta ve şifre doğrulaması olduktan sonra Şekil 3' de gösterildiği gibi basit ekran görüntülenir. Burada yer alan "CHECK GATE" düğmesine basılınca Algorima 1'de gösterildiği gibi kapidaKaldim.php web servisi çalışır. Bu servis Raspberry Pi üzerindeki Python kodunu çağırır. Kapı önünün kameradan görüntüsü alınarak kapidaGoruntu.jpg olarak kaydeden Python kodu Algoritma 2'de gösterildiği gibidir. 


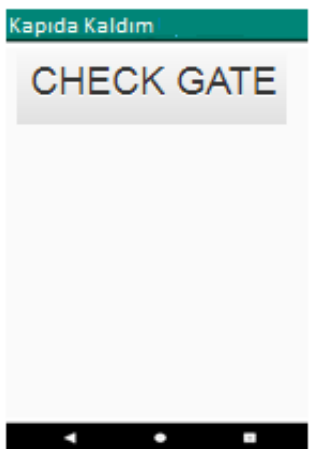

Şekil 3. Kapı açılması için istek gönderme paneli.

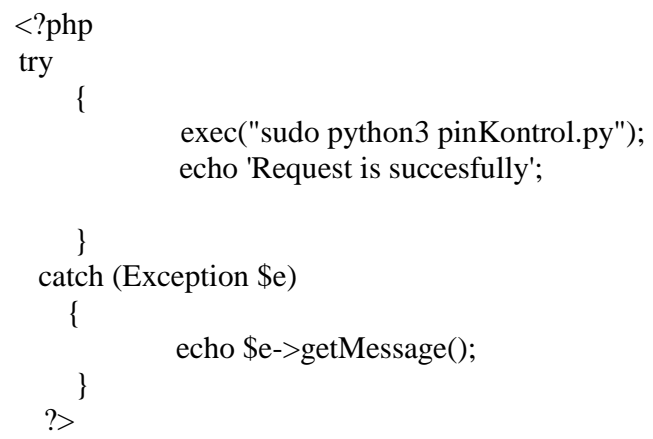

Algoritma 1. kapidaKaldim.php servisi.

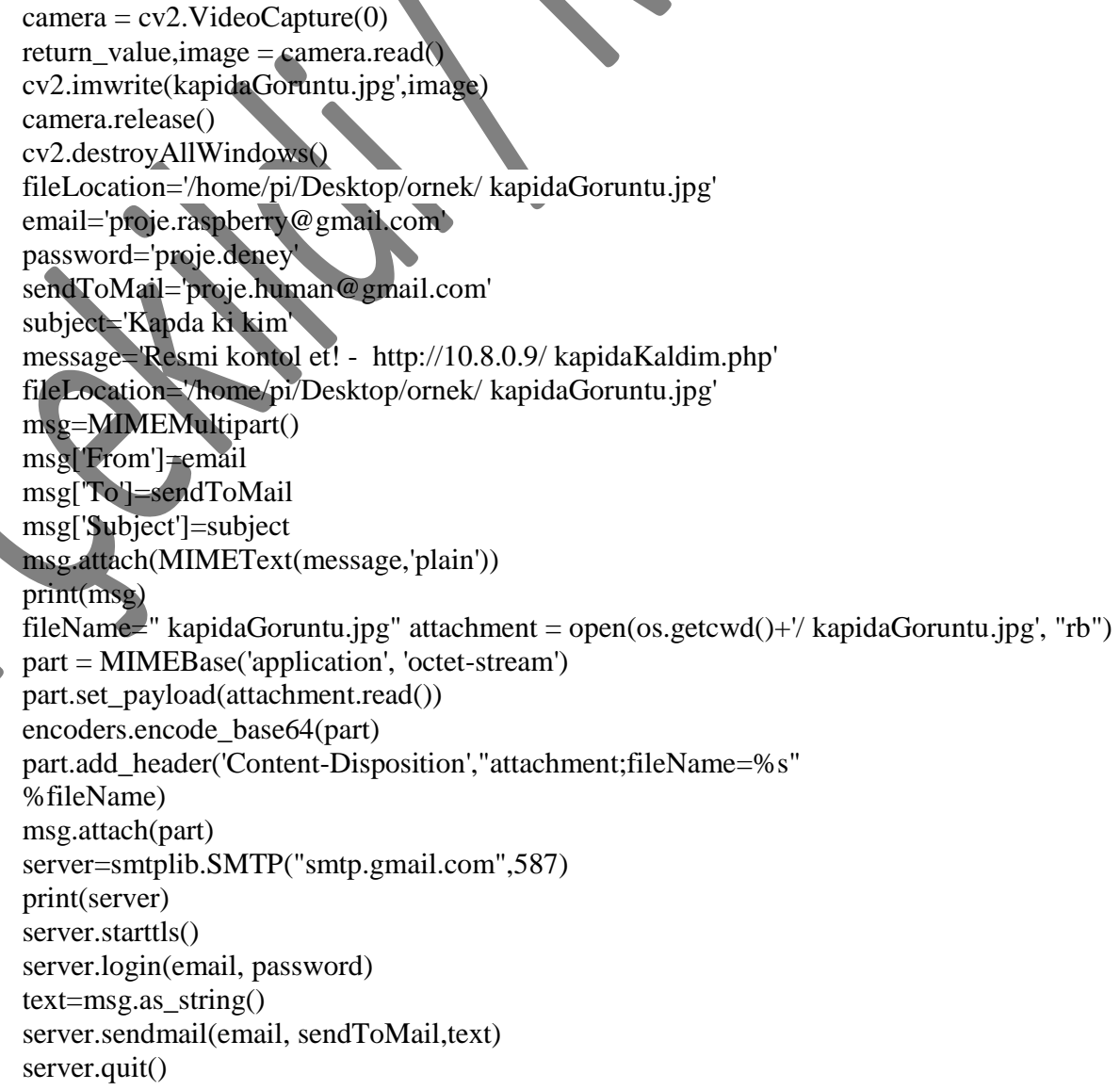

Algoritma 2. Kapı önü kamera görüntüsü alma kodu ve e-posta gönderme kodu.

Raspberry Pi'de kapidaGoruntu.jpg olarak kaydedilen fotoğraf proje.raspberry @gmail.com e-posta adresinden yetişkin bireyin (anne, baba) kullandığı proje.human@gmail.com e-posta adresine gönderilir. Web servisi ile veri iletişimi sağlamak istendiğinden 
Raspberry Pi 'de 5000 portu açılır ve bu porttan veri alınıp, gönderilir. Raspberry Pi üzerinde Flask ile entegre çalışan Algoritma 3' de gösterildiği gibi Python kodları 5000 portuna gelecek taleplerin değerlendirilmesi için kullanılmıştır.

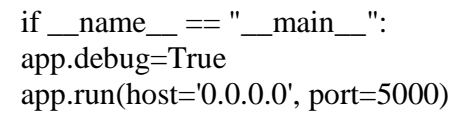

Algoritma 3. Raspberry Pi'ye gelen taleplerin değerlendirilmesi

E-posta ile gelen kapidaGoruntu.jpg resmindeki bireyin tanıdık bir kişi olduğu yetkili kişi tarafindan anlaşıldığında, kendi cep telefonunda bulunan "Kapıyı Aç" Android uygulamasını kullanır. Şifre giriş panelinden doğru bilgileri girdiğinde, Şekil 4'de gösterildiği gibi "TURN ON GATE" düğmesini içeren ekran karşısına gelir. Bu düğmeye basıldığında Algoritma 4'de gösterildiği gibi kapiyiAc.php web servisi çalışır. Bu web servisi Raspberry Pi üzerindeki Algoritma 5' gösterildiği gibi verilen Python kodunu çağırrr. Kod incelendiğinde görüleceği üzere, 7. pin’e verilen gerilimle elektrikli kapı kilidi açılmış olacaktır. 5V'luk röle Raspberty Pi' nin kapı açılma esnasında maruz kalabileceği yüksek akım zararlarından korunması için kullanılmıştır.

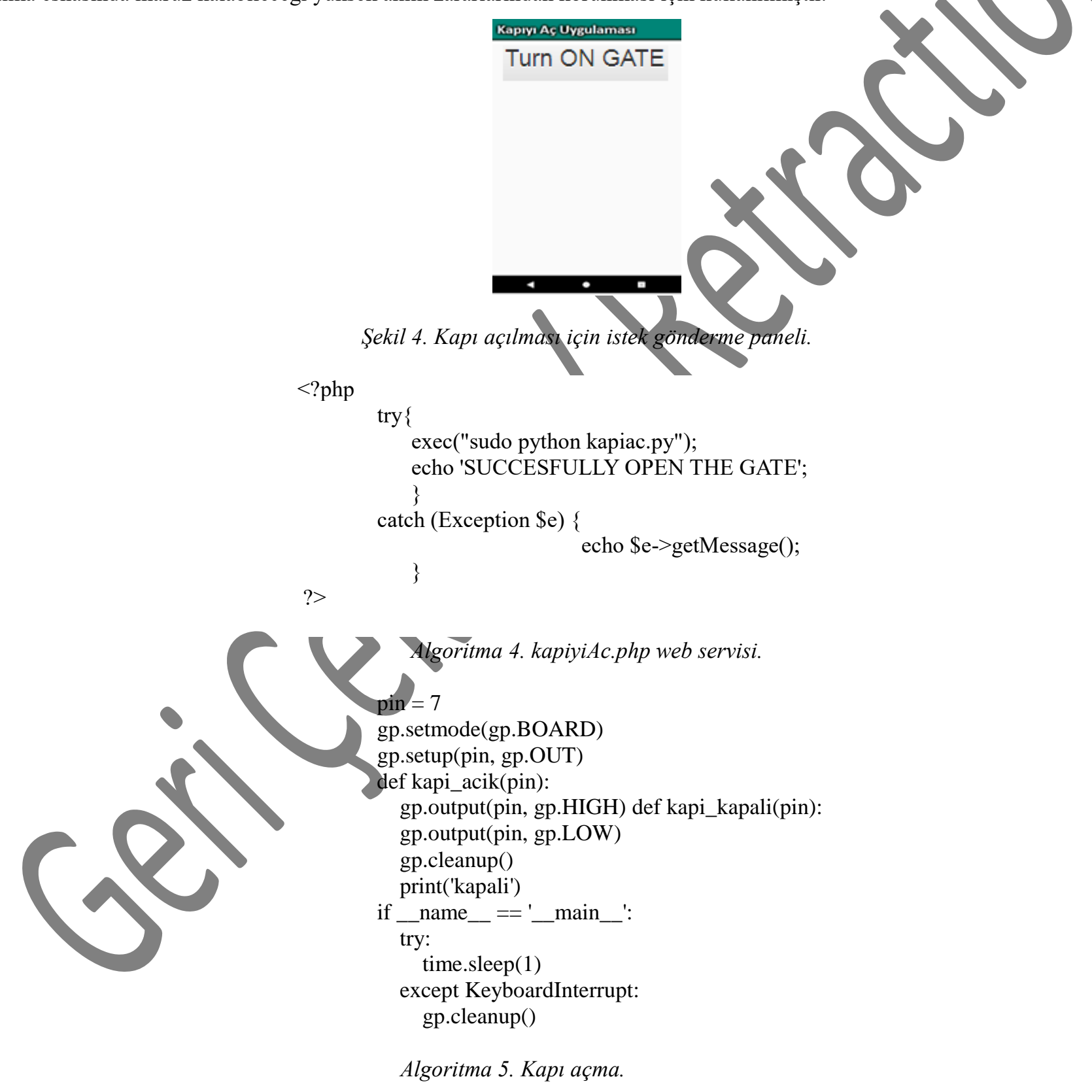

\section{Sonuç ve Öneriler}

Önerilen sistem modelinin bir prototipi Şekil 5'de görülmektedir. Sistemin maksimum güvenlikli olması amacı ile çeşitli teknik çözümler entegre edilmiştir. Örneğin, özel e-posta kullanılarak kapıdaki kişinin görüntüsü güvenli bir biçimde iletilmektedir. Daha da önemlisi, her iki kullanıcı tipi için bağımsız Android uygulamaları geliştirilmiş, yetki girişleri bağımsız kılınmıştır. 


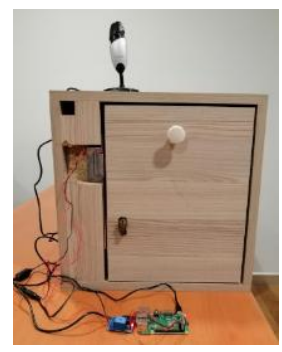

Şekil 5. Önerilen sistem prototipi.

Ayrıca günümüzde siber saldırıların artmasından dolayı, IoT cihazları için güvenlik önlemlerinin alınması zaruri olmuştur. Bu amaçla, internet ağı üzerinden gelebilecek olası saldırılardan korunmak üzere özellikle VPN kullanılmıştır. OpenVPN noktadan noktaya bağlantı kurduğu ve gönderilen veriler şifrelendiği için kullanılmıştır.

Önerilen model, sunduğu üst düzey ve katmanlı güvenlik mimarisinin yanı sıra, maliyet olarak pratik biçimde uygulanabilirdir. Mevcut piyasa koşullarında, Raspberry pi B+ modelin 320 TL, elektrikli kapı kilidi 60 TL, 12V adaptör 20 TL, röle kartı 5 TL olarak ele alındığında, toplam fiyat yaklaşık olarak 405 TL olmaktadır. Sonuç olarak, sadece ev için değil iş yerleri içinde kullanılabilir.

Uygulamanın dezavantajı olarak görülebilecek en önemli unsurlar internet bağlantısının kopması veya elektriğin gitmesi olarak düşünülebilir. Aktif enerji tüketimi az olduğundan, elektrik kesintilerine karşı önlem olarak maliyeti düsük bataryalar kullanılabilir.

\section{Kaynakça}

[1] Selvarasu R, Nehru P, Selvarasu R. (2015). Android mobile based home security and device control using GSM. Sponsored 2nd International Conference on Innovations in Information Embedded and Communication Systems (ICIIECS) 2015 (pp. 1-5) IEEE.

[2] Han D, Kim H, Jang J. (2017) Blockchain based smart door lock system. 2017 International Conference on Information and Communication Technology Convergence (ICTC) 2017 (pp. 1165-1167) IEEE.

[3] Hadis MS, Palantei E, Ilham AA, Hendra A. (2018) Design of smart lock system for doors with special features using bluetooth technology.2018 International Conference on Information and Communications Technology (ICOIACT) 2018 (pp. 396-400) IEEE.

[4] Arifin R, Sarno R. (2018) Door automation system based on speech command and pin using android smartphone. 2018 International Conference on Information and Communications Technology (ICOIACT) 2018 (pp. 667-672) IEEE.

[5] Adalan K, Erkmen B.(2016) Face recognition, nfo and voice controlled door lock system. 2016 National Conference on Electrical, Electronics and Biomedical Engineering (ELECO) 2016 (pp. 696-700) IEEE.

[6] Kavde S, Kavde R, Bodare S, Bhagat G. (2017) Smart digital door lock system using bluetooth technology. 2017 International Conference on Information Communication and Embedded Systems (ICICES) 2017 (pp. 1-4) IEEE.

[7] Mrinal M, Priyanka L, Saniya M, Poonam K, Gavali AB. (2017) Smart Home - Automation and Security System Based on Sensing Mechanism 2017 Second International Conference on Electrical, Computer and Communication Technologies (ICECCT) 2017 (pp. 1-3) IEEE.

[8] Tilala P, Roy AK, Das ML. (2017).Home Access Control through a Smart Digital Locking-Unlocking System. 2017 IEEE Region 10 Conference (TENCON) 2017 (pp. 1409-1414) IEEE.

[9] Vaidya B, Patel A, Panchal A, Mehta R, Mehta K, Vaghasiya P. (2017). Smart home automation with a unique door monitoring system for old age people using Python, OpenCV, Android and Raspberry pi. 2017 International Conference on Intelligent Computing and Control Systems (ICICCS) 2017 (pp. 82-86) IEEE.

[10] Kim T, Park H, Hong SH, Chung Y. (2013). Integrated system of face recognition and sound localization for a smart door phone. IEEE Transactions on Consumer Electronics,59(3), 598-603.

[11] Aman F, Anitha C. (2017) Motion Sensing and Image Capturing based Smart Door System on Android Platform. 2017 International Conference on Energy, Communication, Data Analytics and Soft Computing (ICECDS) 2017 (pp. 2346-2350) IEEE.

[12] Muthumari M, Sah NK, Raj R, Saharia J. (2018) Arduino based Auto Door unlock control system by Android mobile through Bluetooth and Wi-Fi. 2018 IEEE International Conference on Computational Intelligence and Computing Research (ICCIC) 2018 (pp.1-4) YEEE

[13] Park YT, Sthapit P, Pyun JY. (2009) Smart Digital Door Lock for the Home Automation. 2009 IEEE Region 10 Conference 2009 (pp.1-6) IEEE.

[14]Lita AI, Visan DA, Mazare A G.(2017) Door Automation System for Smart Home Implementation. 2017 23rd International Symposium for Design and Technology in Electronic Packaging (SIITME) 2017 (pp. 345-348) IEEE.

[15] Tyagi V, Kumar A. (2017) Internet of Things and social networks: A survey. 2017 International Conference on Computing, Communication and Automation (ICCCA) 2017 (pp. 1268-1270).

[16] Stefanov DH, Bien Z, Bang WC. (2004) The smart house for older persons and persons with physical disabilities: structure, technology arrangements, and perspectives. IEEE Transactions on Neural Systems and Rehabilitation Engineering, 12(2), 228-250.

[17] Aman F, Anitha C. (2017) Motion Sensing and Image Capturing based Smart Door System on Android Platform. 2017 International Conference on Energy, Communication, Data Analytics and Soft Computing (ICECDS) 2017 (pp. 2346-2350) IEEE.

[18] Yamanoor NS, Yamanoor S. (2017) High Quality, Low Cost Education with the Raspberry Pi. 2017 IEEE Global Humanitarian Technology Conference (GHTC) 2017 (pp. 1-5) IEEE. 